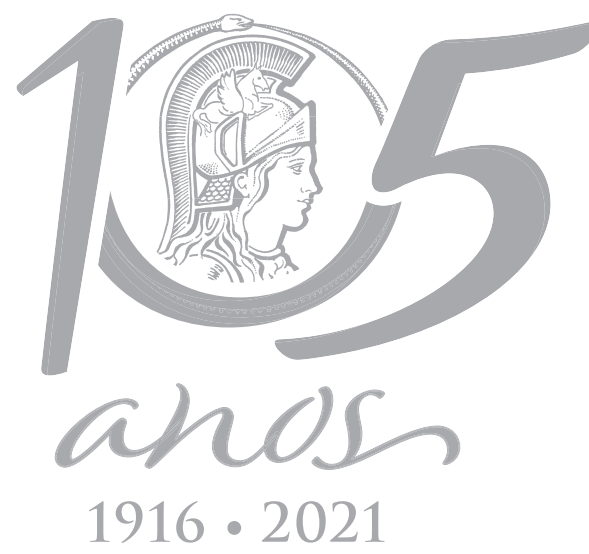

\title{
Preparation, optimization and evaluation of transdermal therapeutic system of celecoxib to treat inflammation for treatment of rheumatoid arthritis
}

\author{
MUHAMMAD NAEEM, TANIYA IQBAL, ZARQA NAWAZ \& SAJJAD HUSSAIN
}

\begin{abstract}
The purpose of present study was to prepare transdermal therapeutic system that could enhance dissolution of poorly aqueous soluble drug Celecoxib and thus increase its skin permeation. Solubility studies screened triacetin as oil, cremophor RH 40 as surfactant and Polyethylene Glycol 400 as co-surfactant. Pseudoternary phase diagrams were constructed to find out microemulsion region. Independent variables (oil, Smix and water) concentration was used at high $(+1)$ and low levels $(-1)$ that would generate 17 different combinations of microemulsions. Microemulsions were characterized, optimized and evaluated. pH, viscosity, conductivities, refractive index, droplet size and poly-dispersity-index was investigated. Prepared microemulsions were oil in water, thermodynamically stable, isotropic, transparent, deflocculated and within narrow range of size. Mathematical equations and response surface plots related the independent and dependent variables. Optimum microemulsion $\mathrm{ME}_{6}$ was further incorporated with carbomer 940 gel base to produce microemulsion based gel. $\mathrm{ME}_{6}$ and its gel showed significant difference $(p<0.05)$ from control gel. Stability studies showed prepared MEBG of celecoxib was stable during storage period. Skin irritation studies found the gel was safe and non-irritating to skin. Anti-inflammatory studies showed significant difference $(p<0.05)$ compared to control gel. Thus, the therapeutic system was successfully developed and optimized using Box Behnken statistical design.
\end{abstract}

Key words: Anti-inflammatory studies, Celecoxib, franz diffusion cell, microemulsion, transdermal therapeutic system.

\section{INTRODUCTION}

The first synthesized non-steroidal antiinflammatory drug (NSAID) Celecoxib showed its effect by selectively inhibiting COX-2 activity. Orally Celecoxib is prescribed for Rheumatoid arthritis, osteoarthritis and acute pain (Frampton \& Keating 2007, Clemett \& Goa 2000). Long term oral delivery of Celecoxib results in serious side effects like gastrointestinal toxicity, gastric mucosal ulceration, hemorrhage and currently, cardio-toxic effects which prohibit its oral usage and make this a suitable candidate for transdermal application. It has very poor aqueous solubility in water $(4 \mathrm{mg} / \mathrm{L})$ and skin barrier function limit its formulation for transdermal dosage forms and make it challenging. Hence its formulation for transdermal dosage form with capability of high degree of skin permeation and safety could be beneficial (Gaurel et al. 1997).

One of the main techniques to enhance the transdermal permeation of drugs is preparation of microemulsion (ME) which act as vehicles (Cevc \& Vierl 2010, Shakeel \& Ramadan 2010). Microemulsion is defined as an oil in water (o/w) or water in oil (w/o) showing a transparent 
shape with droplet size of $<0.2 \mu \mathrm{m}$ (Lawrence $\&$ Rees 2000). This is thermodynamically stable dispersions of water and oil which is stabilized using surfactants alone or in combination with co-surfactants (Kreilgaard 2002, Danielsson \& Lindman 1981, Alany et al. 2000, Rhee et al. 2001). Microemulsion have attained great emphasis for transdermal drug delivery because of ease of preparation, thermodynamic stability, its components permeation enhancement and greater solubilizing ability to many drugs than conventional topical formulation vehicles (Marti \& Nielloud 2002, Ambade et al. 2008, Kamal et al. 2007, Chen et al. 2007, Zhao et al. 2006, Park et al. 2005).

Additionally the little viscosity of microemulsion also inhibits its application for pharmaceutical industry because it does not retain on skin surface (Lawrence \& Rees 2000). The addition of gel bases like carrageenan and carbomer 940 into the microemulsion formulated the gel bases containing microemulsion (Valenta \& Schultz 2004). The gel base containing Microemulsion with high viscosity and powerful permeation capability is considered to deliver optimum concentration of drug (Lapasin et al. 2001).

Thus, the purpose of this study was to develop different combinations for microemulsion preparation using Box Behnken design (BBD). Microemulsion components were generally regarded as safe (GRAS) and enhanced the dissolution and skin permeation. The prepared microsmulsions were subjected to physicochemical characterizations and in vitro permeation studies. Optimum microemulsion was used for formulating MEBG of Celecoxib which produced the sustained effects. In vitro, Anti-inflammatory and skin irritation studies were performed using microemulsion based gel (MEBG) and compared with control gel.

\section{Experimental}

\section{Materials}

Celecoxib was purchased from Getz Pharmaceutical Company Karachi Pakistan. Castor oil, Olive oil, Oleic acid, Isopropyl myristate (IPM), Triacetin, Ethyl oleate, Labrasol, tween 40, tween 80, Labrafil, Cremophor RH 40, Ethanol, propylene glycol, transcutol-P, Polyethylene glycol-400 (PEG 400) were purchased from Merck, Germany.

\section{Methods}

\section{Solubility studies}

The solubility of Celecoxob was conducted to select suitable oil (castor oil, IPM, triacetin, ethyl oleate, olive oil, oleic acid), surfactant (labrasol, tween 40, tween 80, labrafil, cremophor RH 40) and co-surfactant (ethanol, propylene glycol, transcutol-P and PEG-400). An 100 mg of celecoxib was added to $6 \mathrm{ml}$ of oil or surfactant or co-surfactant and the resulting mixture was shaken reciprocally for $72 \mathrm{~h}$ at $37^{\circ} \mathrm{C}$ followed by centrifugation at $12,000 \mathrm{rpm}$ for 10 minutes. The supernatant was filtered using membrane filter paper $(0.45 \mu \mathrm{m})$ and the filtrate was analyzed using UV-Visible spectrophotometer (IRMECO $\mathrm{GmbH}$, Germany) at $251 \mathrm{~nm}$ with suitable dilution. The oil or surfactant or co-surfactant that showed high solubility of celecoxib was employed for the preparation of microemulsions containing 2\% (w/w) celecoxib (Naeem et al. 2019). Celecoxib concentration was determined using linear regression equation $\left(R^{2}=0.96\right)$ as Equation 1:

$y=0.061 x+0.021$

$x$ and $y$ represent the concentration estimation and absorbance measurement, 
respectively. 0.061 depicts slopes and 0.021 depicts the intercept.

\section{Construction of pseudoternary phase diagram for microemulsions}

Screened Triacetin (oil), Cremophore RH 40 (surfactant) and PEG 400 (co-surfactant) were employed to construct the Pseudoternary phase diagrams by water titration method. Surfactant to co-surfactant mixture (Smix) and oil to Smix weight ratios were used at 1:1, 1:2 and 1:3 and; at $1: 9,1: 8,1: 7,1: 6,1: 5,1: 4,1: 3.5,1: 3,1: 2.33,1: 2,1: 1.5,1: 1$, 1:0.67, 1:0.43, 1:0.2 and 1:0.11 respectively (Sahoo et al. 2014).

\section{Box behnken design for optimization}

Oil $\left(X_{1}\right)$, Smix $\left(X_{2}\right)$ and water $\left(X_{3}\right)$ represented the Independent variables and consumed at low $(-1)$ and high $(+1)$ levels. $Q_{24}\left(Y_{1}\right)$, flux $\left(Y_{2}\right)$ and lag time $\left(\mathrm{Y}_{3}\right)$ represented the dependent variables (Gannu \& Rao 2012).

\section{Preparation of celecoxib loaded microemulsion}

Box Behnken design was used to generate 17 different combination of microemulsions. It was formulated as follows: Triacetin (oil) was mixed to mixture of cremophor $\mathrm{RH} 40$ and PEG-400 (Smix). Then the drug was loaded by Ultra-Sonication (Elma, Germany). Water was added drop-wise to the above oily drug mixture using hot plate magnetic stirrer at optimum temperature.

\section{Preparation of celecoxib loaded microemulsion based gel and control gel}

Carbomer 940 was added at 0.50\% (w/w), 0.75\% $(\mathrm{w} / \mathrm{w})$ and $1.00 \%(\mathrm{w} / \mathrm{w})$ concentration separately into the water for preparing gel bases. Then optimized $\mathrm{ME}_{6}$ was added into $0.75 \%$ gel base to prepare microemulsion based gels because it has ideal viscosity and fluidity as compared to
0.50\% and $1.00 \%$ gel bases (Chen et al. 2007). For obtaining control gel, celecoxib was solubilized in water solution containing PEG 400, followed by mixing $0.75 \%(w / w)$ carbomer 940 gel base and adjusting $\mathrm{pH}$.

\section{Characterization}

$\mathrm{pH}$ determination was performed by $\mathrm{pH}$ meter (WTW inolab, Germany). Brookfield RVDV III ultra, Programmable Rheometer (Brookfield Engineering Laboratories, Middleboro, MA) was employed to evaluate the viscosities. Conductometer WTW Cond 197i Weilhein, Germany) was used to analyze the conductivities ( $\sigma$ ). Refractive index was estimated using Ballingham Stanely (RFM 330 plus). Droplet size and Poly-dispersity index determined by the principle Dynamic Light Scattering method using utilizing Zeta sizer (Malvern Nano-ZS, UK). Shape and surface morphology was estimated using Atomic Force Microscopy (AFM, XE-100, PSIA, Korea). Triplicate analysis was conducted for each preparation.

\section{Permeation study}

\section{Preparation of skin}

Advanced Study and Research Board (ASARB) of The Islamia University of Bahawalpur- Pakistan granted approval for conducting this study. Due to the difficulty of obtaining human skin samples, the Rabbit skin was used (Levang et al. 1999). The subcutaneous fat was removed by scalpel, and the epidermis removed by heat separation. This involved immersion of full thickness skin in water at $60^{\circ} \mathrm{C}$ for one minute, followed by careful teasing of the epidermis from the dermis (Chevalier et al. 2008). The thickness of the epidermis samples was measured by micrometer gauge (Mitchell et al. 2004). The epidermis was rinsed with distilled water, wrapped in Aluminium foil and 
stored at $-50^{\circ} \mathrm{C}$ (Ultra-low temperature freezer; Sanyo, Japan) until used. Although epidermis can also be used for in vitro permeation studies immediately after preparation (Rhee et al. 2001, Ozguney et al. 2006).

\section{In vitro permeation studies}

Vertical Franz-type diffusion cell (PermeGear, Bethlehem, PA) was used with an effective diffusional surface area of $1.767 \mathrm{~cm}^{2}$. The receptor compartment volume was $12 \mathrm{ml}$. Phosphate buffer solution (PBS) ( $\mathrm{pH}$ 7.4) was employed as the receptor medium. Before using the Franz cell, the skin was soaked in PBS ( $\mathrm{pH} 7.4$ ) for $12 \mathrm{~h}$ at 4 ${ }^{\circ} \mathrm{C}$ to equilibrate the skin (Ogiso et al. 2001). The receptor chamber was filled with PBS $(\mathrm{pH} 7.4)$ and the skin was clamped between the donor and receptor compartments of the Franz cell, with the stratum corneum side facing the donor compartment. Receptor solution was kept at 37 $\pm 0.2^{\circ} \mathrm{C}$ using water bath and a peristaltic pump. Then it was stirred on hot plate magnetic stirrer at $600 \mathrm{rpm}$ using a Teflon-coated magnet bar. The donor compartment contained $2.0 \mathrm{~g}$ of test microemulsion containing $50 \mathrm{mg}$ of Celecoxib; and was occluded with aluminium foil. This corresponded to infinite dose conditions. $1 \mathrm{~mL}$ of samples were extracted out on particular time intervals $(0,1,2,3,4,5,6,8,10,12,14,16,20$, and 24 hours) and then diluted to $10 \mathrm{~mL}$ using PBS pH 7.4 and analyzed at $251 \mathrm{~nm}$ using a UVspectrophotometer. Concentration of celecoxib permeated at different sampling intervals was determined by measuring the reading of pure celecoxib solution (50 mg drug in $12 \mathrm{ml}$ of PBS $\mathrm{pH}$ 7.4) which was first diluted by extracting 10 $\mu \mathrm{l}$ in a $10 \mathrm{ml}$ volumetric flask and making up the volume with PBS analyzed at $251 \mathrm{~nm}$ using a UV-spectrophotometer.

\section{Permeation data analysis}

Cumulative amount permeated $\left(\mathrm{Q}_{24}\right)$ of Celecoxib was determined and the Celecoxib concentration was then rectified for sampling effects as reported using the following equation relation as Equation 2

$C_{n}^{1}=C_{n}\left(V_{T} / V_{T}-V_{S}\right)\left(C_{n-1}^{1} / C_{n-1}\right)$

where $C_{n}^{1}$ and $C_{n}$ represent the corrected and quantified drug at sample $n^{\text {th }}$, respectively. $C_{n-1}^{1}$ determined the drug concentration in a sample $(n-1)^{\text {th }}, V_{T}$ and $V_{S}$ represent the receiver fluid volume and withdrawn sample, respectively.

In vitro Permeation profile ( $Q_{24}$ versus time) was obtained and linear regression analysis was established to calculate the Celecoxib steady state flux $\left(J_{s s}, \mu g / \mathrm{cm}^{2} / \mathrm{hr}\right)$. Lag time was measured between $\mathrm{Q}_{24}$ ( $\mathrm{Y}$-axis) and time ( $\mathrm{X}$-axis) by intercepting time axis.

Permeability coefficient (Kp) was calculated by dividing the flux with concentration of the drug in formulation. Enhancement ratio (ER) was calculated by ratio of microemulsion flux and control flux (Hayton \& Chen 1982).

\section{Experimental design}

Dependent variables were calculated after performing in vitro studies. Data was then optimized for statistical validation and analyzing main effects, interaction effects and quadratic effects. Design expert software (DES) was employed to construct $1^{\text {st }}, 2^{\text {nd }}$ and quadratic models. BBD was particularly selected because it needs fewer runs than central composite design (CCD) for three or four variables. DES generated the non-linear quadratic model equation and represented as: $\left(Y=b_{0}+b_{1} X_{1}+b_{2} X_{2}+b_{3} X_{3}+b_{12} X_{1} X_{2}\right.$ $+b_{13} X_{1} X_{3}+b_{23} X_{2} X_{3}+b_{11} X_{1}^{2}+b_{22} X_{2}{ }_{2}+b_{33} X_{3}^{2}$ )(Zhao et al. 2006). Checkpoint Analysis and Optimization Model Validation for microemulsion was performed $^{27}$. 


\section{Stability study}

The stability study was performed for formulation $\mathrm{ME}_{6}$ and $\mathrm{MEBG}$ of celecoxib. Centrifugation (Helttich, Germany) was performed for 30 minutes at $3500 \mathrm{rpm}$. Ultralow temperature freezer (Sanyo, Japan) was employed for performing three freeze thaw cycles. Formulations were also placed in amber colored containers at $40 \pm 2^{\circ} \mathrm{C} / 75 \pm 5 \% \mathrm{RH}$ (relative humidity) for a period of six months. Samples were taken at pre-determined time intervals of 1, 2, 3 and 6 months. Formulations were checked for visual clarity, phase separation, transparency, non-grittiness, color change and drug content (Naeem et al. 2017).

\section{Skin irritation studies of MEBG}

Advanced Study and Research Board (ASARB) of The Islamia University of Bahawalpur- Pakistan granted approval for conducting this study. The MEBG was selected as the tested formulations for performing skin irritation studies. It was applied to the shaved skin on the dorsal surface of six Rabbits, and then the rabbits were secured. The animals were observed and investigated for any sign of erythema for a period of 7 days (Chen et al. 2007).

\section{Anti-inflammatory studies}

Advanced Study and Research Board (ASARB) of The Islamia University of Bahawalpur- Pakistan ganted approval for conducting this study. Antiinflammatory studies were performed on Rabbits after dividing them among three groups, with six Rabbits available in each group. Group I was considered as standard (without any treatment). MEBG and control gel of celecoxib were applied onto dorsal skin of Rabbits available in group II and III, respectively. Formalin was applied as standard irritant and used one hour before the application of MEBG and control gel. Experimentation was carried on for 7 days for all
3 groups. MEBG and control gel of celecoxib were applied once daily for one week and applied area was graded and measured using Vernier caliper for appearance and disappearance of edema. In order to take precise measures, calculations were taken in triplicate (Naeem et al. 2019).

\section{Statistical analysis}

One way analysis of variance (ANOVA) and the paired sample t-test was used for comparing and statistically analyzing at $p<0.05$ presented as a minimal significance level. Data was validated in triplicate (mean value \pm S.D).

\section{RESULTS AND DISCUSSION}

\section{Selection of microemulsion Components}

After increasing the solubility of BCS class II Lipophilic drugs like Celecoxib, the permeability of drugs might increased. Table I presents the solubility data of Celecoxib. Drug Solubility $(\mathrm{mg} / \mathrm{mL})$ in Triacetin, Cremophor RH 40 and PEG400 were 98.21, 154.6 and 434.16 respectively. Triacetin (oil), Cremophor RH 40 (surfactant), PEG 400 (co-surfactant) and water were selected as microemulsion components because these showed comparatively high solubility and miscibility among themselves.

\section{Construction of pseudoternary phase diagrams}

The developed pseudo-ternary phase diagrams facilitated to find out area of microemulsion region and concentration ranges for microemulsion components. Lipid based formulations by increment in drug solubility resulted in increased skin permeation. Figure 1 showed the phase diagrams with different weight ratios of Smix. The shaded area represented the translucent microemulsion region. Whereas the region outside represented the turbid region. The largest microemulsion region was developed 
Table I. Solubility of Celecoxib in oils, surfactants and co-surfacatants, values presented are mean \pm SD $(n=3)$.

\begin{tabular}{|c|c|c|c|}
\hline $\begin{array}{c}\text { Serial } \\
\text { number }\end{array}$ & $\begin{array}{c}\text { Components } \\
\text { Oil phases }\end{array}$ & Materials & Average solubility $(\mathrm{mg} / \mathrm{ml})$ \\
\hline \multirow{6}{*}{1} & \multirow{6}{*}{ Oils } & Castor oil & $15.1 \pm 0.5$ \\
\hline & & IPM & $42.52 \pm 0.5$ \\
\hline & & Triacetin & $98.21 \pm 0.2$ \\
\hline & & Ethyl oleate & $20.01 \pm 0.3$ \\
\hline & & Olive oil & $4.2 \pm 0.7$ \\
\hline & & Oleic acid & $0.80 \pm 0.12$ \\
\hline \multirow{5}{*}{2} & \multirow{5}{*}{ Surfactants } & Labrasol & $120.01 \pm 0.83$ \\
\hline & & Tween 40 & $137.52 \pm 0.28$ \\
\hline & & Tween 80 & $150.51 \pm 0.26$ \\
\hline & & Labrafil & $29.27 \pm 0.41$ \\
\hline & & Cremophor RH 40 & $154.6 \pm 0.23$ \\
\hline \multirow{4}{*}{3} & \multirow{4}{*}{ Cosurfactants } & Ethanol & $80 \pm 0.345$ \\
\hline & & Propylene glycol & $25.82 \pm 0.451$ \\
\hline & & Transcutol-P & $125.31 \pm 0.3$ \\
\hline & & PEG-400 & $434.16 \pm 21.56$ \\
\hline
\end{tabular}

at Smix ratio of 1:1. These area decreased as the Smix was increased to 1:2 and 1:3. Huang et al also presented the narrowing of isotropic region with increased Smix in the oil poor part of phase diagrams. The Smix ratio at 1:1 was selected to prepare microemulsion and then loaded with Celecoxib (Huang et al. 2008).

\section{Physicochemical characteristics}

$\mathrm{pH}$ of all prepared microemulsions was in range of 4.39-4.91. This pH showed mild skin irritation. After incorporation of microemulsion into the Gel base of Carbomer 940, pH of MEBG of celecoxib was 5.5 that was comparable with skin. This $\mathrm{pH}$ value is safe to skin and non irritating. The droplet size of microemulsion was found in nano range of (61-96) nm. Optimized $\mathrm{ME}_{6}$ showed droplet size $60 \mathrm{~nm}$ after measurement using zeta sizer and AFM. Zeta potential determined was $-0.171 \mathrm{mV}$. Droplets of optimized ME6 were deflocculated and uniformly distributed into the system and no adhesion or aggregation was observed. (Figure 2) (Fanun et al. 2010).

The conductivity of all 17 microemulsion preparations was in range 133-184. As water concentration increased it would resulted in increased conductivity. Increase in conductivity was due to increase in surfactant dissociation as function of water concentration. (Park et al. 2005).

The viscosity (CP) of microemulsion was in range of (63-169). It was increased as the concentration of Smix increased. It was due to the hydrophilic chain of non-ionic surfactant which was strongly hydrated and connected together using hydrogen bonds causing strong interactions (Boonme et al. 2006). 


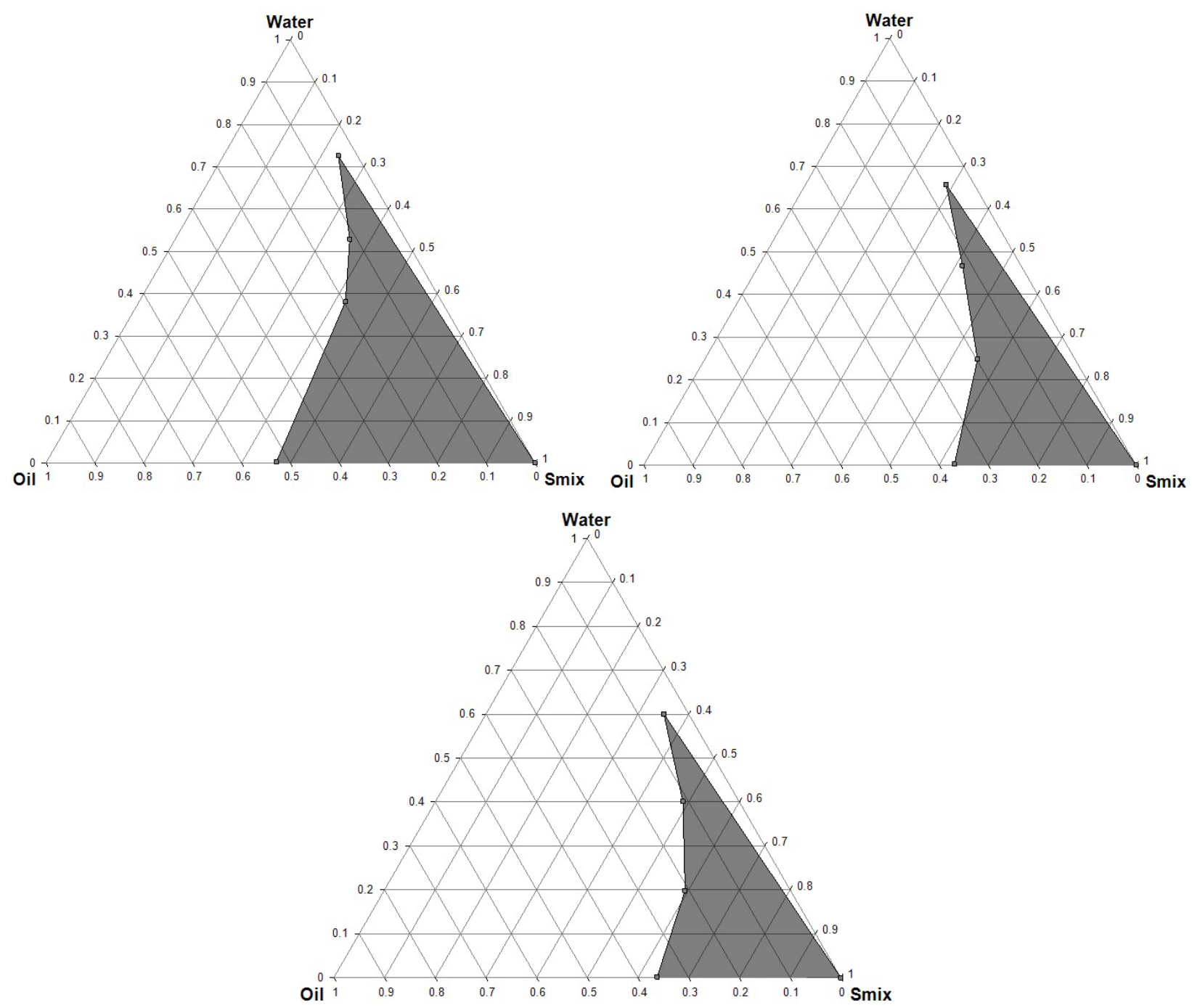

Figure 1. Pseudoternary phase diagrams of microemulsions using Smix at weight ratio a) 1:1 b) 1:3 and c) 1:5.

Range of refractive index of microemulsion preparations was in 1.323-1.428 that signified the microemulsion preparations were clear and transparent (Lapasin et al. 2001). Polydispersity index (PDI) shows homogeneity of droplets and it was in 0.129-0.392 ranges. It depicted microemulsion droplets in narrow size distribution (Table II) (Naeem et al. 2019).

\section{In vitro skin permeation experiments}

Permeation studies using Rabbit skin was conducted for microemulsions, MEBG and control gel. Permeation parameters $\left(Q_{24}\right.$, flux and lag time) were calculated for all prepared microemulsions. $\mathrm{Q}_{24}$, flux and lag time were $102-290 \mu \mathrm{g} / \mathrm{cm}^{2}, 4-14.5 \mu \mathrm{g} / \mathrm{cm}^{2} / \mathrm{h}$ and 1.20-1.95 $\mathrm{hr}$, respectively, for prepared microemulsions. Permeability coefficient (Kp) and Enhancement ratio MEs were 5.1-14.5 and 1.33-4.83 respectively (Table III).

$\mathrm{Q}_{24}$ and flux was decreased when the concentration of Smix increased from $45 \%$ to $50 \%$ at fixed oil concentration. Celecoxib was highly soluble in Smix. The thermodynamic activity of celecoxib in microemulsions was a significant driving force for the release and penetration 


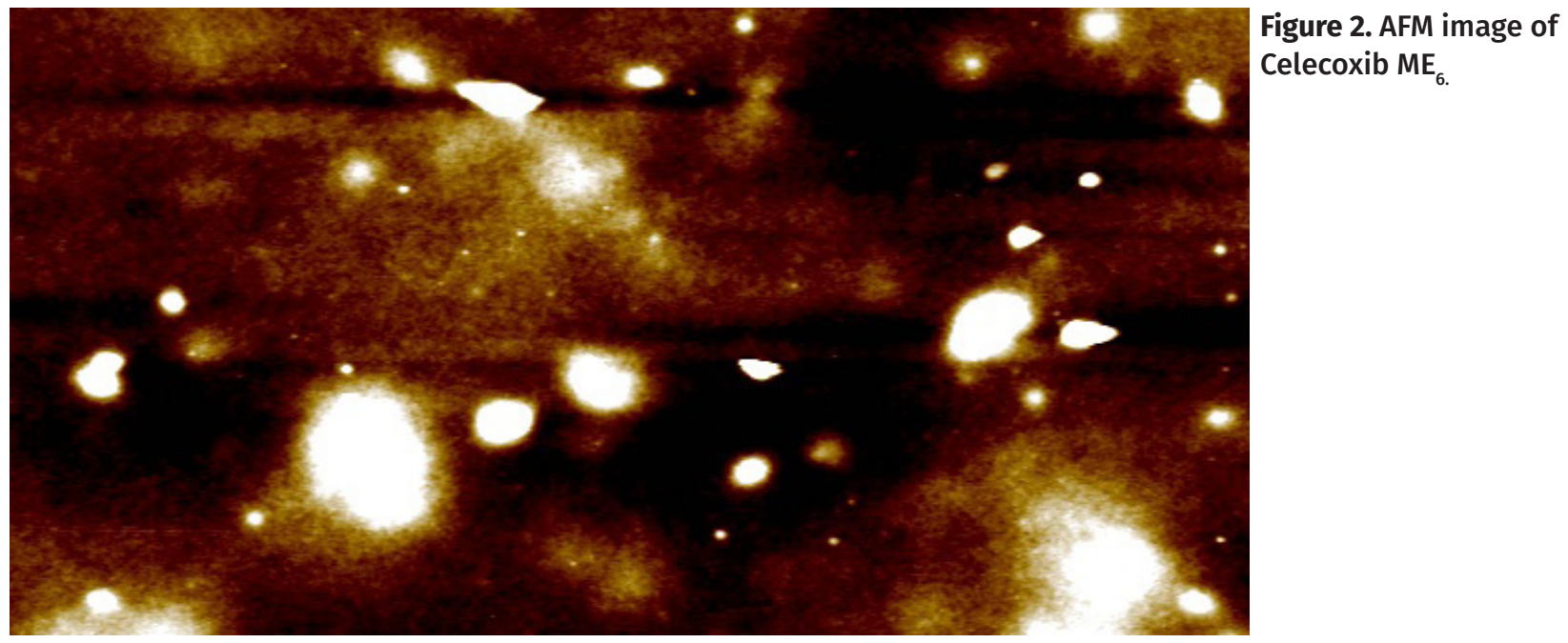

of drug into skin at lower Smix concentration. Hence increase in Smix concentration would decrease the $\mathrm{Q}_{24}$ and flux. When the triacetin concentration was increased from $10 \%$ to $20 \%$ at fixed Smix concentration, the solubility of drug increased and resulted in decreased thermodynamic activity of drug. It would result in decrease permeation across skin. Additionally a lipophilic drug is preferentially loaded into the oil phase and the highly drug loaded system favor partition into the epidermis resulting in enhanced flux (Ngawhirunpat et al. 2013).

$\mathrm{ME}_{12}$ exhibited higher $\mathrm{Q}_{24}\left(290 \mu \mathrm{g} / \mathrm{cm}^{2}\right)$ and flux $\left(14.5 \mu \mathrm{g} / \mathrm{cm}^{2} / \mathrm{h}\right)$ and; lowest lag time (1.2 hr). So therefore the chosen optimized $M E_{12}$ was loaded with $0.75 \%$ gel base of Carbomer 940 to fabricate MEBG of Celecoxib. MEBG exhibited $\left.270 \mu \mathrm{g} / \mathrm{cm}^{2}\right), 12.8 \mu \mathrm{g} / \mathrm{cm}^{2} / \mathrm{h}$ and 1.31 hour for $\mathrm{Q}_{24}$, flux and lag time, respectively. Control gel preparation exhibited $40 \mu \mathrm{g} / \mathrm{cm}^{2}, 3 \mu \mathrm{g} / \mathrm{cm}^{2} / \mathrm{h}$ and $2.81 \mathrm{hr}$ for $\mathrm{Q}_{24}$, flux and lag time, respectively.

When compared to celecoxib $M_{6}$, a significant $(p<0.05)$ decrease in $Q_{24}$ was observed after mixing $\mathrm{ME}_{6}$ with Carbomer 940 gel base. Besides, lag time to fabricate MEBG was 1.31 hour that was significantly $(p<0.05)$ greater than $M_{6}$ lag time. ER of $\mathrm{ME}_{6}$ and $\mathrm{MEBG}$ were 5 and 4 times higher as compared with control formulation.
In vitro studies of $\mathrm{ME}_{6}, \mathrm{MEBG}$ and control gel formulations are depicted in Figure 3.

\section{Formulation optimization}

Independent variables along with their responses are depicted in Table III. $\mathrm{ME}_{2}, \mathrm{ME}_{7}$, $M E_{11}, M E_{12}$ and $M E_{13}$ have same composition of oil, Smix and water. So these showed same values of $\mathrm{Q}_{24}$, Flux and Lag time. Two dimensional contour plots and three dimensional response surface plots (Figure 4) are beneficial for studying the interaction effects of the factors on the responses at one time. In all the depicted figures, the $3^{\text {rd }}$ factor was considered at a constant level. All the relationships among the 3 variables are non-linear, while exhibiting almost a linear relationship of Factor $X_{1}$ (triacetin) with Factors $X_{2}$ (Smix) and $X_{3}$ (water), in the form of almost straight lines up to the medium Smix level (Figure 4). At higher Smix these become nonlinear or curvilinear. Factors $X_{2}$ (Smix) and $X_{3}$ (water) have curvilinear relationship at all levels of the two variables on the response $Y_{2}$ (flux). The $Y_{1}\left(Q_{24}\right)$ and flux $\left(Y_{2}\right)$ were increased with increasing concentrations of either oil $\left(X_{1}\right)$ or Smix $\left(X_{2}\right)$ (up to medium level) at constant concentration of water phase $\left(X_{3}\right)$. The model demonstrated could be represented as Eq. 4,5,6: 
Table II. Characterization of MEs.

\begin{tabular}{|c|c|c|c|c|c|c|}
\hline Codes & $\mathrm{pH}$ & $\begin{array}{l}\text { Conductivity } \\
\sigma(\mu S / \mathrm{cm})\end{array}$ & $\begin{array}{l}\text { Viscosity } \\
\text { (cP) }\end{array}$ & $\begin{array}{c}\text { Refractive } \\
\text { Index }\end{array}$ & $\begin{array}{l}\text { Poly Dispersity } \\
\text { Index }\end{array}$ & $\begin{array}{l}\text { Average Droplet } \\
\text { Size }(\mathrm{nm})\end{array}$ \\
\hline $\mathrm{ME}_{1}$ & 4.76 & $184 \pm 3.1$ & $63 \pm 0.45$ & 1.419 & $0.129 \pm 0.021$ & 96 \\
\hline$M E_{2}$ & 4.66 & $182 \pm 2.1$ & $65 \pm 0.34$ & 1.349 & $0.138 \pm 0.027$ & 63 \\
\hline $\mathrm{ME}_{3}$ & 4.91 & $139 \pm 1.4$ & $169 \pm 0.41$ & 1.428 & $0.365 \pm 0.016$ & 91 \\
\hline $\mathrm{ME}_{4}$ & 4.68 & $161 \pm 1.7$ & $88 \pm 0.98$ & 1.355 & $0.254 \pm 0.014$ & 74 \\
\hline $\mathrm{ME}_{5}$ & 4.80 & $143 \pm 2.9$ & $115 \pm 0.77$ & 1.378 & $0.262 \pm 0.015$ & 81 \\
\hline $\mathrm{ME}_{6}$ & 4.82 & $159 \pm 2.5$ & $107 \pm 0.80$ & 1.401 & $0.252 \pm 0.028$ & 91 \\
\hline $\mathrm{ME}_{7}$ & 4.39 & $169 \pm 3.5$ & $75 \pm 0.55$ & 1.423 & $0.165 \pm 0.010$ & 95 \\
\hline $\mathrm{ME}_{8}$ & 4.64 & $163 \pm 1.1$ & $125 \pm 0.63$ & 1.370 & $0.293 \pm 0.026$ & 79 \\
\hline $\mathrm{ME}_{9}$ & 4.81 & $165 \pm 2.6$ & $110 \pm 0.70$ & 1.3301 & $0.269 \pm 0.024$ & 60 \\
\hline$M E_{10}$ & 4.87 & $154 \pm 2.7$ & $113 \pm 0.61$ & 1.370 & $0.296 \pm 0.013$ & 77 \\
\hline$M E_{11}$ & 4.89 & $149 \pm 2.8$ & $133 \pm 0.53$ & 1.370 & $0.359 \pm 0.011$ & 76 \\
\hline$M E_{12}$ & 4.73 & $159 \pm 1.3$ & $106 \pm 0.67$ & 3.371 & $0.279 \pm 0.022$ & 61 \\
\hline$M E_{13}$ & 4.51 & $142 \pm 1.6$ & $149 \pm 0.36$ & 1.425 & $0.379 \pm 0.020$ & 66 \\
\hline $\mathrm{ME}_{14}$ & 4.69 & $161 \pm 2.5$ & $105 \pm 0.65$ & 3.323 & $0.286 \pm 0.019$ & 73 \\
\hline$M E_{15}$ & 4.59 & $133 \pm 3.5$ & $155 \pm 0.78$ & 1.428 & $0.392 \pm 0.017$ & 79 \\
\hline$M E_{16}$ & 4.52 & $179 \pm 1.5$ & $77 \pm 0.50$ & 1.401 & $0.152 \pm 0.012$ & 88 \\
\hline$M E_{17}$ & 4.84 & $171 \pm 1.3$ & $85 \pm 0.75$ & 1.359 & $0.235 \pm 0.023$ & 72 \\
\hline
\end{tabular}

$Y_{1}\left(Q_{24}\right)=189-9.50 X_{1}-85 X_{2}-2.5 X_{3}+0.001 X_{1} X_{2}+$ $1 X_{1} X_{3}+0.002 X_{2} X_{3}-1.50 X_{1}^{2}+8.50 X_{2}^{2}-3.00 X_{3}^{2}$

$Y_{2}$ (Flux $)=8.70-0.71 X_{1}-4.46 X_{2}-0.23 X_{3}+0.025 X_{1} X_{2}$ $+0.002 X_{1} X_{3}+0.001 X_{2} X_{3}+0.037 X_{1}^{2}+0.49 X_{2}^{2}-0.19$ $\mathrm{x}_{3}^{2}$

$\mathrm{Y}_{3}($ Lag time $)=1.56+0.049 \mathrm{X}_{1}+0.31 \mathrm{X}_{2}+0.012 \mathrm{X}_{3}$

A positive value favours for optimization while the negative value depicts the inverse relationship for factors with responses. Table IV depicted the summary of results of regression analysis for responses $Y_{1}, Y_{2}$, and $Y_{3}$ to be fitted for quadratic model. It was noticed for responses $Y_{1}$, $Y_{2}$, and $Y_{3}$, the Predicted $R^{2}$ is found in reasonable agreement with Adjusted $R^{2}$. Adequate Precision determined the signal to noise ratio. A ratio greater than 4 is desirable. In present study ratio indicated an adequate signal (Gannu \& Rao 2012). 
Table III. Variables and observed responses in Box Behnken Design for microemulsions.

\begin{tabular}{|c|c|c|c|c|c|c|c|c|}
\hline \multirow[t]{2}{*}{ ME Code } & \multicolumn{3}{|c|}{ ME Components } & \multirow{2}{*}{$\begin{array}{c}\mathbf{Q}_{24} \\
\mu \mathrm{g} / \mathrm{cm}^{2}\end{array}$} & \multirow{2}{*}{$\begin{array}{c}\text { Flux } \\
\mu \mathrm{g} / \mathrm{cm}^{2} / \mathrm{h}\end{array}$} & \multirow{2}{*}{$\begin{array}{l}\text { Lag } \\
\text { Time } \\
\text { hour }\end{array}$} & \multirow[t]{2}{*}{ ER } & \multirow{2}{*}{$\begin{array}{l}\text { Permeability Coefficient } \\
\qquad \mathrm{Kp} \times 10^{-3} \\
(\mathrm{~cm} / \mathrm{h})\end{array}$} \\
\hline & Oil & Smix & Water & & & & & \\
\hline ME1 & 15 & 40 & 24 & 281 & 13.7 & 1.25 & 4.57 & 0.685 \\
\hline ME2 & 15 & 47.5 & 29.5 & 189 & 8.7 & 1.55 & 2.90 & 0.435 \\
\hline ME3 & 15 & 40 & 35 & 278 & 13.2 & 1.27 & 4.40 & 0.66 \\
\hline ME4 & 10 & 55 & 29.5 & 120 & 5.5 & 1.8 & 1.83 & 0.275 \\
\hline ME5 & 20 & 47.5 & 35 & 172 & 7.7 & 1.6 & 2.57 & 0.385 \\
\hline ME6 & 10 & 40 & 29.5 & 290 & 14.5 & 1.2 & 4.83 & 0.725 \\
\hline ME7 & 15 & 47.5 & 29.5 & 189 & 8.7 & 1.55 & 2.90 & 0.435 \\
\hline ME8 & 15 & 55 & 35 & 108 & 4.3 & 1.89 & 1.43 & 0.215 \\
\hline ME9 & 20 & 47.5 & 24 & 177 & 8.1 & 1.57 & 2.70 & 0.405 \\
\hline ME10 & 10 & 47.5 & 24 & 199 & 9.4 & 1.5 & 3.13 & 0.47 \\
\hline ME11 & 15 & 47.5 & 29.5 & 189 & 8.7 & 1.55 & 2.90 & 0.435 \\
\hline ME12 & 15 & 47.5 & 29.5 & 189 & 8.7 & 1.55 & 2.90 & 0.435 \\
\hline ME13 & 15 & 47.5 & 29.5 & 189 & 8.7 & 1.55 & 2.90 & 0.435 \\
\hline ME14 & 20 & 55 & 29.5 & 102 & 4 & 1.95 & 1.33 & 0.2 \\
\hline ME15 & 10 & 47.5 & 35 & 190 & 9 & 1.53 & 3.00 & 0.45 \\
\hline ME16 & 20 & 40 & 29.5 & 272 & 12.9 & 1.3 & 4.30 & 0.645 \\
\hline ME17 & 15 & 55 & 24 & 111 & 4.8 & 1.87 & 1.60 & 0.24 \\
\hline
\end{tabular}

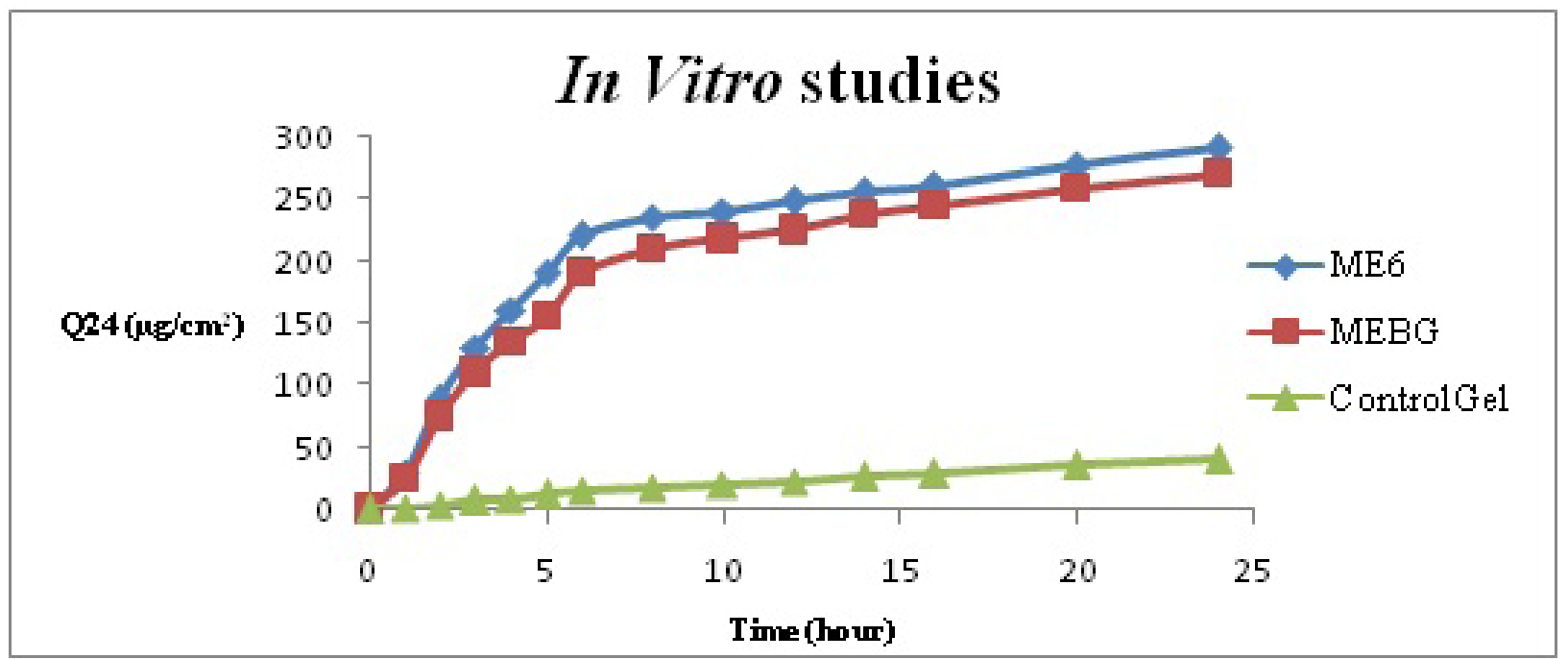

Figure 3. In vitro permeation profiles of Celecoxib loaded $\mathrm{ME}_{6}, \mathrm{MEBG}$ and control $(\mathrm{n}=3)$. 

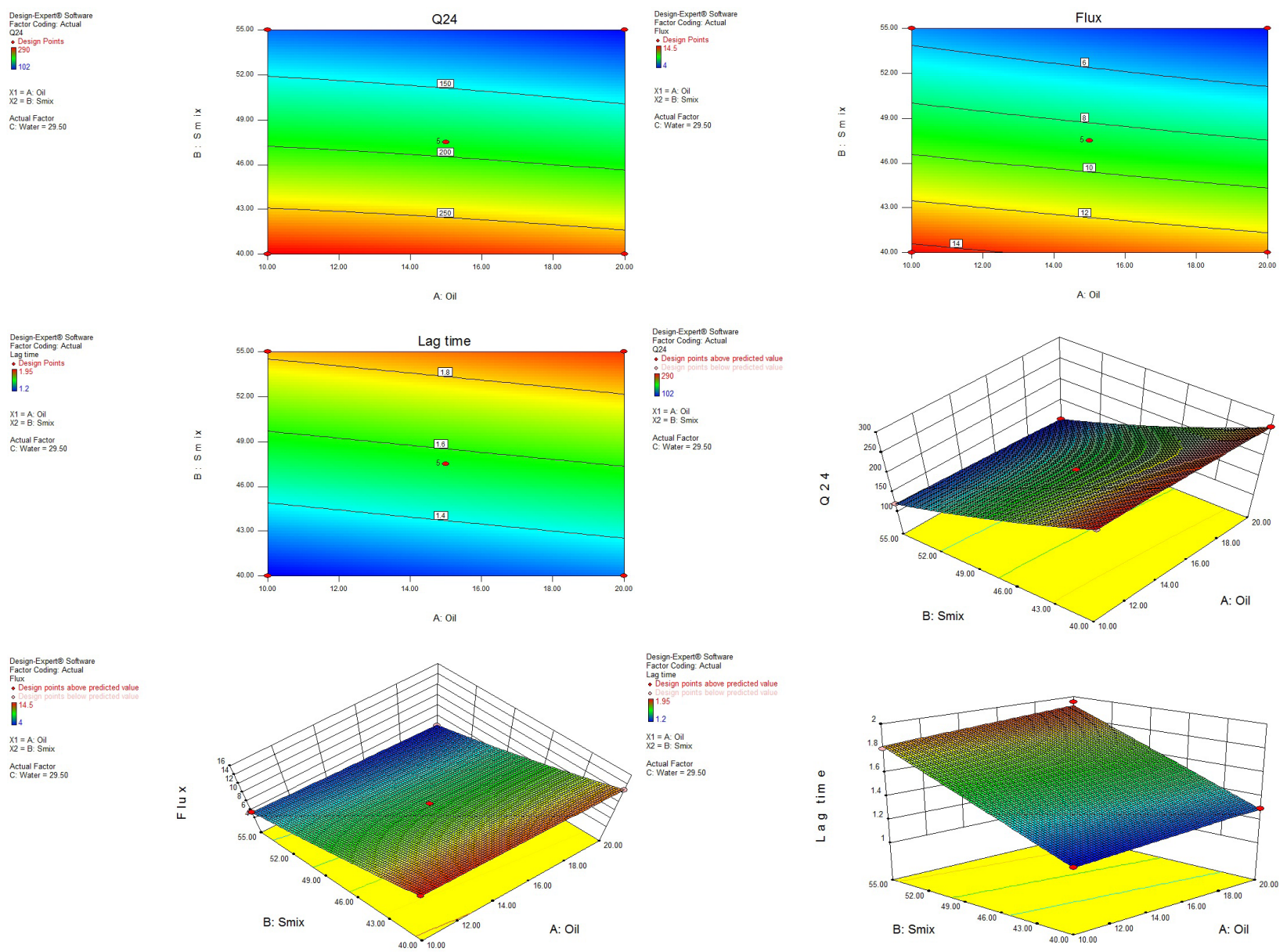

Figure 4. Contour plot showing effects (a) $Q_{24}$ (b) Flux (c) Lag Time corresponding response surface plots (d - $f$ ).

Table IV. Summary of results of regression analysis for responses $Y_{1}, Y_{2}$, and $Y_{3}$ for fitting to quadratic model.

\begin{tabular}{|c|c|c|c|c|c|c|}
\hline Response & $\mathbf{r}^{2}$ & Adjusted $\mathbf{r}^{2}$ & Predicted $\mathbf{r}^{2}$ & Adequate precision & S.D & \%CV \\
\hline$Y_{1}$ & 0.9998 & 0.9996 & 0.9973 & 206 & 0.63 \\
\hline$Y_{2}$ & 0.9999 & 0.9995 & 0.9964 & 184 & 0.073 & 0.83 \\
\hline$Y_{3}$ & 0.9957 & 0.9947 & 0.9914 & 91 & 0.016 & 1.04 \\
\hline
\end{tabular}




\section{Thermodynamic stability studies}

Visual examination depicted the optimized microemulsion preparations were stable when subjected to centrifugation and freeze thaw cycles. Optimized $\mathrm{ME}_{6}$ and $\mathrm{MEBG}$ presented Celecoxib concentration of $99 \%$ and $99.3 \%$, respectively for six months duration. Results elaborated the Celecoxib found stable for the whole duration of study. The results showed that the formulations did not show significant difference $(p>0.05)$ in permeation profiles compared to that of initial permeation profiles indicating that both the formulations are stable. Formuations were clear and transparent and; did not show any phase separation and color change. (Naeem et al. 2013).

\section{Skin irritation studies}

The skin irritation studies could not find any irritation, erythyma indicating that the MEBG of celecoxib is non-irritant (Gannu \& Rao 2012).

\section{Anti-inflammatory studies}

Edema was induced by using Formalin and model was applied for distinguishing the antiinflammatory activity of MEBG and conventional gel of Celecoxib. Significant difference $(p<0.05)$ was observed when compared the edema percentage for MEBG (89\%) and control gel (49\%) compared to standard (without using gel) (Naeem et al. 2019) (Figure 5). The enhanced anti-inflammatory effects of the MEBG could be due to the enhanced permeation of celecoxib through the skin.

\section{CONCLUSION}

Solubility and permeability of newly established transdermal therapeutic system was increased. BBD optimized the dependent and independent variables. Mathematical equations and regression equations selected the quadratic equation as best fit model. $\mathrm{ME}_{6}$ loaded celecoxib was selected as the optimum preparation to formulate MEBG. It was transparent, thermodynamically stable, deflocculated and in narrow size range. Contour and 3D RSP exhibited nearly the linear relationship of factors. It showed decrease oil and Smix concentrations increased thermodynamic activity of drug and thus increased in permeation of Celecoxib. System was safe, stable and non-irritating to skin. It exhibited the significantly $(p<0.05)$ greater anti-inflammatory activity as compared

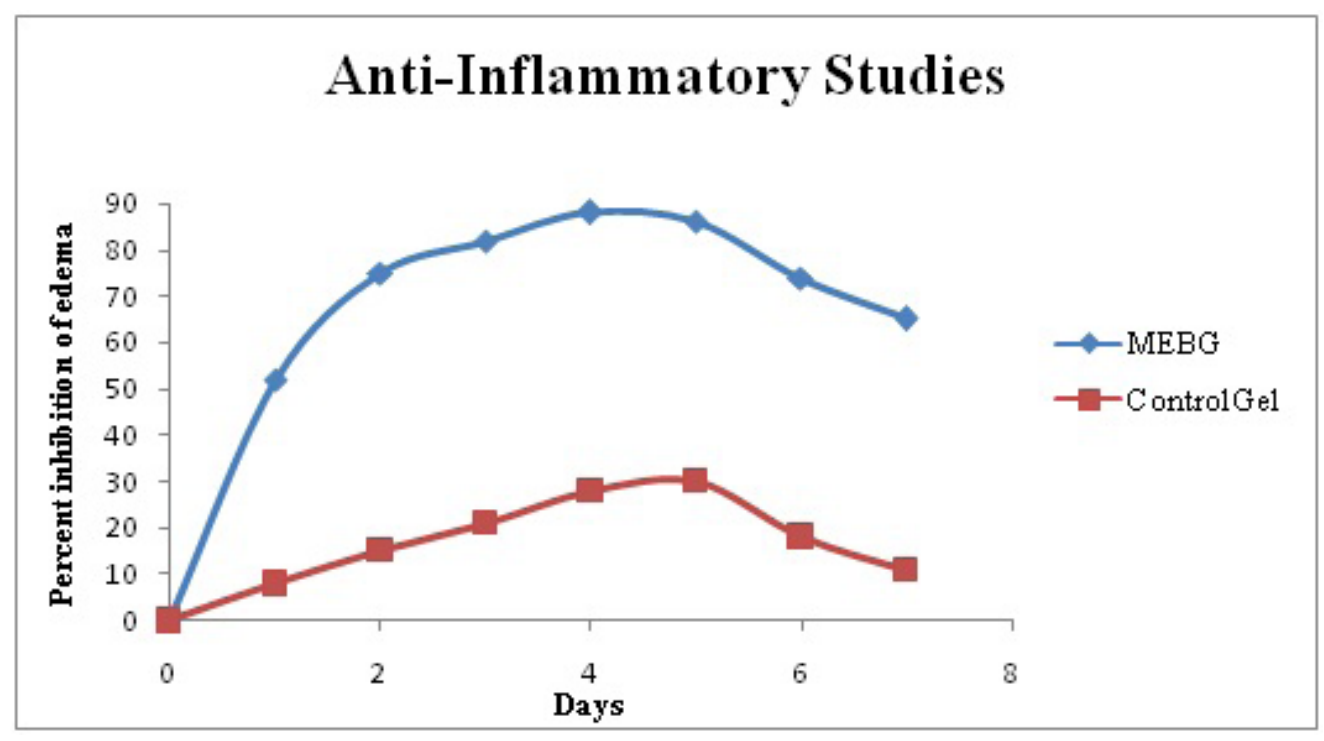

Figure 5. Antiinflammatory activity of MEBG and control gel of Celecoxib. 
with control gel. So it was determined that the current work investigated the quite novel approaches and could be further evaluated for BCS-ll drugs.

\section{Acknowledgments}

The authors would like to thank Faculty of Pharmacy and Alternative Medicine, the Islamia University of Bahawalpur, Bahawalpur, Pakistan, for providing Reserach Laboratory Services.

\section{REFERENCES}

ALANY RG, RADES T, AGATONOVIC-KUSTRIN S, DAVIES NM \& TUCKER IG. 2000. Effects of alcohols and diols on the phase behaviour of quaternary systems. Int J Pharm 196(2): 141-145.

AMBADE KW, JADHAV KR, GAMBHIRE MN, KURMI SD, KADAM VJ \& JADHAV KR. 2008. Formulation and evaluation of flurbiprofen microemulsion. Curr Drug Deliv 5(1): 32-41.

BOONME P, KRAUEL K, GRAF A, RADES T \& JUNYAPRASERT VB. 2006. Characterization of microemulsion structures in the pseudoternary phase diagram of isopropyl palmitate/water/Brij 97: 1-butanol. AAPS Pharmscitech 7(2): E99-E104.

CEVC G \& VIERL UJ. 2010. Nanotechnology and the transdermal route: A state of the art review and critical appraisal. J Control Release 141(3): 277-299.

CHEN H, MOU D, DU D, CHANG X, ZHU D, LIU J, XU H \& YANG $X$. 2007. Hydrogel-thickened microemulsion for topical administration of drug molecule at an extremely low concentration. Int J Pharm 341(1-2): 78-84.

BOLZINGER MA, BRIANÇON S, PELLETIER J, FESSI H \& CHEVALIER Y. 2008. Percutaneous release of caffeine from microemulsion, emulsion and gel dosage forms. Eur J Pharm Biopharm 68(2): 446-451.

CLEMETT D \& GOA KL. 2000. Celecoxib. Drugs 59(4): 957-980.

DANIELSSON I \& LINDMAN B. 1981. The definition of microemulsion. Colloids Surf 3(4): 391-392.

FANUN M, MAKHARZA S \& SOWWAN MJ. 2010. UV-Visible and AFM Studies of Nonionic Microemulsions. J Dispers Sci Technol 31(4): 501-511.

FRAMPTON JE \& KEATING GM. 2007. Celecoxib. Drugs 67(16): 2433-2474.

GANNU R \& RAO YM. 2012. Formulation optimization and evaluation of microemulsion based transdermal therapeutic system for nitrendipine. J Dispers Sci Technol 33(2): 223-233.

GAUREL A, MARTEL AM \& CASTANER J. 1997. Celecoxib, antiinflammatory, cyclo-oxygenase-2 inhibitor. Drug Future 22(7): 711-714.

HAYTON WL \& CHEN T. 1982. Correction of perfusate concentration for sample removal. J Pharm Sci 71(7): 820-821.

HUANG YB, LIN YH, LU TM, WANG RJ, TSAI YH \& WU PC. 2008. Transdermal delivery of capsaicin derivative-sodium nonivamide acetate using microemulsions as vehicles. Int J Pharm 349(1-2): 206-211.

KAMAL MA, LIMURA N, NABEKURA T \& KITAGAWA S. 2007. Enhanced skin permeation of diclofenac by ion-pair formation and further enhancement by microemulsion. Chem Pharm Bull 55(3): 368-371.

KREILGAARD M. 2002. Influence of microemulsions on cutaneous drug delivery. Adv drug deliver Rev 54: S77-S98.

LAPASIN R, GRASSI M \& COCEANI N. 2001. Effects of polymer addition on the rheology of o/w microemulsions. Rheol Acta 40(2): 185-192.

LAWRENCE MJ \& REES GD. 2000. Microemulsion-based media as novel drug delivery systems. Adv drug deliver Rev 45(1): 89-121.

LEVANG AK, ZHAO K \& SINGH J. 1999. Effect of ethanol/ propylene glycol on the in vitro percutaneous absorption of aspirin, biophysical changes and macroscopic barrier properties of the skin. Int J Pharm 181(2): 255-263.

MARTI-MESTRES G \& NIELLOUD F. 2002. Emulsions in health care applications-an overview. J Dispers Sci Technol 23(13): 419-439.

MITCHELL SC, KENYON S, CARMICHAEL PL, KHALAQUE S, PANCHAL S, WARING R, HARRIS R \& SMITH RL. 2004. The passage of trimethylamine across rat and human skin. Food Chem Toxicol 42(10): 1619-1628.

NAEEM M, NAWAZ Z, IQBAL T, HUSSAIN S, YOUSUF $M$, KHAN JA, IDREES HA \& ALI A. 2019. Microemulsion and microemulsion based gel of Zaleplon for transdermal delivery: Preparation, optimization, and evaluation. Acta Pol Pharm 76(3): 543-561.

NAEEM M, PERVAIZ F, NAWAZ Z, YOUSUF M, ALI A, KHALID N \& KHAN JA. 2017. A quality by design approach: Fabrication, characterization and evaluation of optimized transdermal therapeutic system for antirheumatic lornoxicam. Acta Pol Pharm 74(1): 249-266. 
NAEEM M, RAHMAN NU, KHAN JA, SEHTI A \& NAWAZ Z. 2013. Development and optimization of microemulsion formulation using Box-Behnken design for enhanced transdermal delivery of Lornoxicam. Lat Am J Pharm 32(8): 1196-1204.

NGAWHIRUNPAT T, WORACHUN N, OPANASOPIT P, ROJANARATA T \& PANOMSUK S. 2013. Cremophor RH40-PEG 400 microemulsions as transdermal drug delivery carrier for ketoprofen. Pharm Dev Technol 18(4): 798-803.

OGISO T, HATA T, IWAKI M \& TANINO T. 2001. Transdermal absorption of bupranolol in rabbit skin in vitro and in vivo. Biol Pharm Bull 24(5): 588-591.

OZGUNEY IS, KARASULU HY, KANTARCI G, SOZER S, GUNERI T \& ERTAN G. 2006. Transdermal delivery of diclofenac sodium through rat skin from various formulations. AAPS PharmSciTech 7(4): E39-E45.

PARK ES, CUI Y, YUN BJ, KO IJ \& CHI SC. 2005. Transdermal delivery of piroxicam using microemulsions. Arch Pharm Res 28(2): 243-248.

RHEE YS, CHOI JG, PARK ES \& CHI SC. 2001. Transdermal delivery of ketoprofen using microemulsions. Int J Pharm 228(1-2): 161-170.

SAHOO S, PANI NR \& SAHOO SK. 2014. Microemulsion based topical hydrogel of sertaconazole: Formulation, characterization and evaluation. Colloids Surf B Biointerfaces 120: 193-199.

SHAKEEL F \& RAMADAN W. 2010. Transdermal delivery of anticancer drug caffeine from water-in-oil nanoemulsions. Colloids Surf B Biointerfaces 75(1): 356-362.

VALENTA C \& SCHULTZ K. 2004. Influence of carrageenan on the rheology and skin permeation of microemulsion formulations. J Control Release 95(2): 257-265.

ZHAO X, LIU J, ZHANG X \& LI Y. 2006 Enhancement of transdermal delivery of theophylline using microemulsion vehicle. Int J Pharm 327(1-2): 58-64.

\section{How to cite}

NAEEM M, IQBAL T, NAWAZ Z \& HUSSAIN S. 2021. Preparation, optimization and evaluation of transdermal therapeutic system of celecoxib to treat inflammation for treatment of rheumatoid arthritis. An Acad Bras Cienc 93: e20201561. DOI 10.1590/0001-3765202120201561.
Manuscript received on December 21, 2020;

accepted for publication on July 1, 2021

\section{MUHAMMAD NAEEM ${ }^{1}$}

https://orcid.org/0000-0003-3368-8270

\section{TANIYA IQBAL ${ }^{2}$}

https://orcid.org/0000-0003-1061-528X

\section{ZARQA NAWAZ 3}

https://orcid.org/0000-0003-4251-3069

\section{SAJJAD HUSSAIN ${ }^{4}$}

https://orcid.org/0000-0003-0635-1461

${ }^{1}$ Department of Pharmacy, Shah Abdul Latif University, old national highway, Khairpur, 66020 Sindh, Pakistan

${ }^{2}$ Institute of Chemical Sciences, Bahauddin Zakariya University, Bosan Road, 60000 Multan, Pakistan

${ }^{3}$ Department of Chemistry, The Islamia University of Bahawalpur, Hasilpur road, 63100 Bahawalpur, Pakistan

${ }^{4}$ Department of Zoology, University of Agriculture, University road, police line, 38000 Faisalabad, Pakistan

Correspondence to: Muhammad Naeem

E-mail:naeem.mahar@salu.edu.pk

\section{Author contributions}

Muhammad Naeem generated the idea and executed it successfully into practical work. He prepared the therapeutic system. Then he characterized the preparations. He also optimized the preparation using BBD. Furthermore, he performed the in vitro studies, stability studies, skin irritation studies and Anti-Inflammatory studies. Taniya Iqbal facilitated in statistical analysis, Zarqa Nawaz helped in data collection, Sajjad Hussain co-operated for handling the Rabbits.

\section{(cc) BY}

